\title{
White coat hypertension and obstructive sleep apnea
}

\author{
Li Li Li-zhu Guo* \\ Cardiovascular Center, Beijing Tong Ren Hospital, Capital University of Medical Sciences, 100730 Beijing, China
}

\begin{abstract}
Mini Review
White coat hypertension (WCH) was presented first time by Pickering in 1988 and is characterized by elevated office BP but normal reading when measured outside the office with either ABPM or HBPM [1]. The prevalence of $\mathrm{WCH}$ is from $13 \%$ to $35 \%$ in different populations $[2,3]$. Although most studies have shown scarcely difference of allcause mortality or CVD risks between $\mathrm{WCH}$ and normotensive people [4], WCH patients have a 1.5-2.0-fold higher risk of developing sustained hypertension than normotensive controls after 10 years [5], especially for those people who are older, obesity, or black race $[3,6]$. Obstructive sleep apnea (OSA) is characterized by recurrent collapse of the upper airways during sleep, inducing intermittent episodes of apnea/hypopnea, hypoxemia, and sleep disruption [7], and is one of the risk factors for cardiovascular diseases, such as hypertension, coronary heart disease and cerebrovascular diseases, heart failure and atrial fibrillation [8]. Studies demonstrated that hypertension highly prevalent in OSA, and the presence of OSA is associated with an increased incident of resistant hypertension $[9,10]$.
\end{abstract}

However, fewer studies evaluated BP characteristics of $\mathrm{WCH}$ patients with OSA and the relationship between the two. In our study, WCH patients with OSA presented significantly increased daytime and nighttime BP and decreased diurnal difference in SBP, which means higher rate of "non-dipper" BP. It is the no-dipper status predicted the sustain hypertension happened, and eventually, $42.8 \%$ of the $\mathrm{WCH}$ patients with OSA developed sustained hypertension after 26 months [11].

WCH may be associate with nervous, psychological and metabolism. Patients with $\mathrm{WCH}$ respond to hospital environments and doctors, and are easily excessive nervous and active sympathetic nervous, and presented with a high level adrenaline, renin, aldosterone and cortisol [12]. Hosaka also revealed psychology factor because WCT patients have bar to fit the environment and often depress their emotion [13]. Insulin resistance, metabolic syndrome, abnormal glucose tolerance is suggested concern to WCH. A large Meta-analysis has shown that WCH have highly CVDs incidents, but no difference in all-cause mortality [14].

OSA is chronic intermittent hypoxemia and the consequent is sympathetic nervous activity, RASS activity, oxidative stress injury, systemic inflammatory response etc. WCH patients with OSA have a higher WASO and lower percent of III-IV sleep stages, which suggests that OSA augments sympathetic neural drive to the heart and to the peripheral circulation [11]. Garcia-Rio et al. examined OSA and WCH and reported that $\mathrm{WCH}$ was a frequent phenomenon in patients with OSA, and $73 \%$ of patients with OSA and WCH have non-dipper BP during the nighttime, and particularly the non-dipper DBP, became the main predictive factor for sustained hypertension in our study $[11,15]$. Non-dipper DBP status is due to increased peripheral arterial resistance from the sympathetic vasoconstriction effect of apnea and by excessive vascular sensitivity to sympathetic stimulation from changes to the endothelial response [16]. So, WCH may represent a prehypertension status, which could develop into sustained hypertension with OSA.

BPM is one of important detecting methods to distinguish the WCH from sustained hypertension in adults $[1,17]$. When ABPM resources are not readily available, HBPM (home BP monitoring) provides a reasonable but less desirable alternative to screen for $\mathrm{WCH}$, although the overlap with ABPM is only $60 \%$ to $70 \%$ for detection of WCH $[18,19]$. We should monitor ABPM for OSA patients, and WCH patients should detect OSA by polysomnography, especially for those with risk factors of OSA.

Modified lifestyle is an adaptive for patients with OAS and WCH, and ARB and CCB are the best choice of medicine. Some studies found that improving OSA by CPAP can decrease blood pressure. But other studies demonstrated that there are no benefits in decreasing CVDs by CPAP to moderate-severe OSA patients [20]. Further studies are expected to explore the mechanism between $\mathrm{WCH}$ and OSA, and provide effective treatment method.

\section{References}

1. Whelton PK, Carey RM, Aronow WS, Casey DE Jr, Collins KJ, et al. (2017) ACC AHA/AAPA/ABC/ACPM /AGS/APhA/ASH/ASPC/NMA/PCNA Guideline for the Prevention, Detection, Evaluation, and Management of High Blood Pressure in Adults. Hypertension 71: e127-248. [Crossref]

2. Pickering TG, James GD, Boddie C, Harshfield GA, Blank S, et al. (1988) How common is white coat hypertension? JAMA 259: 225-228.

3. Piper MA, Evans CV, Burda BU, Margolis KL, O'Connor E, et al. (2015) Diagnostic and predictive accuracy of blood pressure screening methods with consideration of rescreening intervals: a systematic review for the U.S. Preventive Services Task Force. Ann Intern Med 162: 192-204. [Crossref]

4. Fagard RH, Cornelissen VA (2007) Incidence of cardiovascular events in white-coat, masked and sustained hypertension versus true normotension: a meta-analysis. $J$ Hypertens 25: 2193-2198. [Crossref]

5. Mancia G, Facchetti R, Bombelli M, Grassi G, Sega R (2006) Longterm risk of mortality associated with selective and combined elevation in office, home, and ambulatory blood pressure. Hypertension 47: 846-853. [Crossref]

6. Mancia G, Bombelli M, Brambilla G, Facchetti R, Sega R, et al. (2013) Long-term prognostic value of white coat hypertension: an insight from diagnostic use of both ambulatory and home blood pressure measurements. Hypertension 62: 168-174. [Crossref]

7. Parati G, Lombardi C, Hedner J, Bonsignore MR, Grote L, et al. (2012) Position paper on the management of patients with obstructive sleep apnea and hypertension: joint recommendations by the ESH/ERS/n, by the European Respiratory Society and by the members of ECOST ACTION B26 on obstructive sleep apnea. J Hypertens 30: 633646. [Crossref]

${ }^{*}$ Correspondence to: $\mathrm{Li} \mathrm{Li} \mathrm{Li-zhu} \mathrm{Guo,} \mathrm{Cardiovascular} \mathrm{Center,} \mathrm{Beijing} \mathrm{Tong} \mathrm{Ren}$ Hospital, Capital University of Medical Sciences, 100730 Beijing, China, E-mail: ellentmc2010@hotmail.com

Received: August 31, 2018; Accepted: September 10, 2018; Published: September 14, 2018 
8. Marin JM, Carrizo SJ, Vicente E, Agusti AG (2005) Long-term cardiovascular outcomes in men with obstructive sleep apnoea-hypopnoea with or without treatment with continuous positive airway pressure: an observational study. Lancet 365: 10461053. [Crossref]

9. Marin JM, Agusti A, Villar I, Forner M, Nieto D, et al. (2012) Association between treated and untreated obstructive sleep apnea and risk of hypertension. JAMA 307 : 2169-2176. [Crossref]

10. Pedrosa RP, Drager LF, Gonzaga CC, Sousa MG, de Paula LK, et al. (2011) Obstructive sleep apnea: the most common secondary cause of hypertension associated with resistant hypertension. Hypertension 58: 811-817. [Crossref]

11. Li L, Guo LZ, Li J, Wang Y, Liu X, et al. (2015) White coat hypertension and obstructive sleep apnea. Sleep Breath 19: 1199-1203. [Crossref]

12. Andrikou I, Tsioufis C, Dimitriadis K (2011) Similar levels of lowgrade inflammation and arterial stiffness in masked and whitecoat hypertension: comparisons with sustained hypertension and normotension. Blood Press Monit 16: 218-223.

13. Hosaka M1, Mimura A, Asayama K, Ohkubo T, Hayashi K, et al. (2010) Relationship of dysregulation of glucose metabolism with white-coat hypertension:the Ohasama study. Hypertens Res 33: 937-943. [Crossref]
14. Briasoulis A, Androulakis E, Palla M, Papageorgiou N, Tousoulis D (2016) White-coat hypertension and cardiovascular events: a meta-analysis. J Hypertens 34: 593.

15. García-Río F, Pino JM, Alonso A, Arias MA, Martínez I, et al. (2004) White coat hypertension in patients with obstructive sleep apnea-hypopnea syndrome. Chest 125 : 817-822.

16. Baguet JP, Barone-Rochette G, Pépin JL (2009) Hypertension and obstructive sleep apnoea syndrome: current perspectives. J Hum Hypertens 23: 431-443.

17. National Clinical Guideline Centre (2011) Hypertension: The Clinical Management of Primary Hypertension in Adults: Update of Clinical Guidelines 18 and 34. London, UK: Royal College of Physicians

18. Siu AL (2015) U.S. Preventive Services Task Force. Screening for high blood pressure in adults: U.S. Preventive Services Task Force recommendation statement. Ann Intern Med 163: 778-786.

19. Bayó J, Cos FX, Roca C, Dalfó A, Martín-Baranera MM, et al. (2006) Home blood pressure selt-monitoring: diagnostic performance in white-coat hypertention. Blood Press Monit 11: 47-52. [Crossref]

20. McEvoy RD, Antic NA, Heeley E, Luo Y, Ou Q, et al. (2016) CPAP for prevention of cardiovascular events in obstructive sleep apnea. N Engl J Med 375: 919-931.

Copyright: $@ 2018$ Li-zhu LLG. This is an open-access article distributed under the terms of the Creative Commons Attribution License, which permits unrestricted use, distribution, and reproduction in any medium, provided the original author and source are credited. 